\title{
A binomia de duas almas poéticas irmanadas: Bocage na obra de Álvares de Azevedo
}

\author{
Adriano Lima Drumond ${ }^{1}$
}

RESUMO: Analisamos, neste artigo, a presença da obra de Manuel Maria du Bocage e de sua imagem biográfica na obra de Álvares de Azevedo.

ABSTRACT: This article analyses the presence of Manuel Maria du Bocage's work and biographical image in the work by Álvares de Azevedo.

PALAVRAS-CHAVE: Álvares de Azevedo; Bocage; Romantismo; Pré-romantismo; Neoclassicismo

KEYWORDS: Álvares de Azevedo; Bocage; Romanticism; Pre-romanticism; Neoclassicism

Na obra de Álvares de Azevedo, composta tanto pela parte propriamente literária (com livros como Lira dos vintes anos, Noite na taverna, Macário, O conde Lopo) quanto pelos discursos e pela parte crítica (na qual se contam textos como o estudo sobre Jacques Rolla, de Alfred de Musset), um grupo de autores marca presença constante, seja em epígrafes e outras intertextualidades, seja em referências biográficas, constituindo, desse modo, uma espécie de panteão literário eleito pelo poeta brasileiro. Nesse grupo, os nomes de Byron, Musset, Lamartine e Shakespeare figuram como os mais importantes, o que grande parcela da fortuna crítica sobre Álvares de Azevedo reproduz. Tomando como referência justamente toda a tradição exegética azevediana, a presença de um determinado autor - de direito e de fato,

1 Mestre em Teoria da Literatura pela FALE/UFMG e doutorando em Estudos comparados de literaturas de lingua portuguesa pela FFLCH/USP. 
sem dúvida, membro daquele referido panteão literário - vem sendo, predominantemente, desprezada. Seu nome: Manuel Maria du Bocage.

Com efeito, na leitura da opera omnia do romântico brasileiro, deparamo-nos com a presença bocagiana em vários lugares e de formas variadas. Para nos atermos às aparições explícitas, temos: 1) a citação do verso "Cantando a vida como o cisne a morte", como uma das epígrafes de Lira dos vinte anos; 2) no poema "O Editor", pertencente à segunda parte dessa mesma obra, a menção ao nome do autor de Rimas, 3) assim como na estrofe XXV do primeiro canto de $O$ poema do frade, 4) numa fala de Penseroso, personagem de Macário, e 5) na segunda parte do primeiro artigo sobre Jacques Rolla, de Alfred de Musset; 6) em nota ao quarto artigo desse mesmo estudo, a expressividade 'terna' de certos momentos da poesia bocagiana é comparada à de duas estrofes de Torquato Tasso; 7) o poeta português Bocage, no prefácio a $O$ conde Lopo, parece ser refutado como autor de certos poemas "infames, corrompidos e corruptores" (AZEVEDO,2000, p.378), tradicionalmente a ele atribuídos e 8) aparece como personagem no poema lírico-dramático "Glória moribunda"; 9) em Noite na taverna, o velho que interrompe a narrativa de Bertram lembra-se de ter bebido com o poeta de Setúbal, e, 10) no estudo ensaístico Literatura $e$ civilização em Portugal, há toda uma seção dedicada a ele. Assim, não apenas a recorrência, mas a diversidade de modos com que Manuel Maria du Bocage, explicitamente, aparece na obra de Álvares de Azevedo (desde a citação do nome à construção de um personagem ficcional - o que não vemos ter ocorrido com nenhum outro poeta do panteão do autor brasileiro) revela a dimensão da importância do poeta português.

Neste artigo, não nos propomos a levantar hipóteses que explicariam esse certo apagamento de Bocage na obra azevediana por parte da crítica $^{2}$. Tratar-se-ia de uma longeva atitude lusófobonacionalista, possivel preferência em remarcar ressonâncias de autores

2 O artigo "Portugal, nação melancólica: Bocage interpretado por Álvares de Azevedo", do prof. Doutor Jaime Guinzburg, docente da USP, seria uma honrosa exceção nesse quadro. O texto consta em nossas referências bibliográficas. 
ingleses, franceses, alemães em oposição a ressonâncias de autores da ex-metrópole, dentro de um propósito de afirmação de independência política e livre-arbítrio cultural, já muito clara em Sílvio Romero?3 Deixemos isso para artigo posterior. Aqui nos interessa exclusivamente o que teria conduzido Álvares de Azevedo a eleger para o seu panteão literário o poeta português, a imagem deste autor e de sua obra na obra do brasileiro e como essa imagem nos pode ajudar a entender a concepção poético-literária azevediana.

A historiografia literária sempre destacou, na obra de Bocage, certas características poéticas, no que se refere à temática e à linguagem, destoantes dos procedimentos típicos do neoclassicismo, estética que ainda predominaria nas letras portuguesas até pelo menos vinte anos após a morte do poeta de Setúbal, quando Almeida Garrett publica Camões, o marco de início do romantismo em Portugal. Óscar Lopes e António José Saraiva, em História da literatura portuguesa, por exemplo, ensinam que Bocage "é já romântico por temperamento, apesar de muito vocabulário e muito alegorismo arcádicos e dos seus laivos de iluminismo"(p.656), índole poética que conduziria, muitas vezes, sua poesia a render-se a uma

[...] imaginação sedenta do hórrido ou do horrendo, de horríssimos furores: tempestades reais ou miticas, crimes lendários, históricos ou noticiados nas gazetas, pesadelos, agonias frenéticas, visões de antros ou abismos, minuciosas descrições de beberagens, esconjuros e outros bruxedos. (SARAIVA; LOPES, [s.d.], p.657. Itálico dos autores).

\footnotetext{
3 Cf ROMERO. In: AZEVEDO, 2000, p.26-43. Levando mais adiante essa hipótese, talvez pudéssemos articulá-la com ideias de Abel Barros Baptista, que, em "O cânone em formação: a teoria da literatura brasileira de Antonio Candido", afirma haver o projeto literário dos modernistas de 22 estabelecido, como paradigma crítico, "a possibilidade de desconhecer Portugal 'pura e simplesmente', dando esse desconhecimento como resultado natural do processo de 'formação' da literatura brasileira". (BAPTISTA, 2005, p.43) Como veríamos, o paradigma crítico ter-se-ia estabelecido no Brasil bem antes. Outra hipótese (menos áspera): nas obras mais lidas e publicadas de Álvares de Azevedo - Lira dos vinte anos, Macário e Noite na taverna-, de fato, essa presença bocagiana não é tão evidente quanto em obras menos conhecidas, como no poema não coligido em nenhum volume "Glória moribunda" e o ensaio Literatura e civilização em Portugal (cuja proposta se mostra na contracorrente do discurso nacionalista disseminado em nosso romantismo).
} 
Massaud Moisés acresce sobre a obra do que considera o "maior poeta do século XVIII português" (p. 119) a notícia da presença de "estertôres, confissões dramáticas de experiências vivas na carne lacerada", isto é, tratar-se-ia de uma poética marcada pelo "pessoalismo" (p.121). Moisés também não deixa de assinalar o prenúncio romântico ou a preparação "para o advento das verdades novas" a serem trazidas "pelo Romantismo" (p.124). Desse modo, nas palavras ainda de Massaud Moisés, "a obra bocageana tornou-se a grande ponte de ligação entre o melhor da poesia quinhentista, a de Camões, e a que vingaria no Romantismo, caracterizada essencialmente pelo signo da revolta e da mais profunda insatisfação"(p.124). Embora os portugueses Óscar Lopes e António J. Saraiva não compartilhem dessa visão enaltecedora sobre a poesia do setecentista, principalmente no que se refere à linguagem, os três assinalam sua forte propensão estilística para o coloquial, mais um indício de afastamento em relação à estética neoclássica que se expressou, via de regra, de modo tão estilizado.

Hernâni Cidade, em seu livro dedicado ao poeta, procura esclarecer tanto sua personalidade biográfica quanto poética em termos de sintonia com o ambiente político-cultural do período:

Tendo vivido de 1765 a 1805, seria o Poeta já por exteriores motivos de cronologia, mesmo que o não fosse por intrínsecas razões de temperamento, um ser de transição, oscilando, na vida, como na arte nela radicada, entre tendências opostas e em conflito. Com efeito, o último quartel do século XVIII e o primeiro do XIX são, em Portugal como na Europa ou no mundo europeizado, a fase intercalar de duas culturas sucessivas, que, se bem subjacentemente uma se continue na outra, em aspectos de superficie se repelem e digladiam. // Não é preciso dizer que se toma aqui a designação de idade clássica, em que Bocage foi educado, e a de idade romântica, que o Poeta sob vários aspectos anunciou, não como dois receituários de expressão literária, mas como duas atitudes de homem em face do mundo e da vida, da natureza e de Deus. (2005, p. 91-92).

Cidade, preferindo classificá-lo como pré-romântico - o que teria sido, segundo o crítico, na "obra como na vida" - ainda acentua: 
Na verdade, nenhuma obra no tempo foi mais de que a de Bocage (e pouquíssimos, como a de Filinto [Elísio] e a de José Anastácio da Cunha, o foram tanto) a projecção da própria vida pessoal, a tradução ou, melhor, a natural conversão em forma literária e em ritmo poético de todos os estremecimentos do coração e reacções da inteligência experimentados na vida pessoal. (2005,p.92-93).

A título de exemplo que especificamente nos importa para 0 ambiente ultra-romântico onde Álvares de Azevedo escreveu sua obra, tomemos o tema da morte. Embora a tradição neoclássica não deixasse de atribuir à personificação da morte o célebre dito latino "et in Arcadia ego", assunto ao qual Erwin Panofsky (2009, p.377-409) dedica excelente e conhecido estudo, há certo tom relativo ao tratamento do assunto na obra de Manuel Maria du Bocage que não pertenceria a uma voz árcade, mas pré-romântica. Os tercetos abaixo, extraídos do soneto "Sobre a sepultura de Tirsália":

Domicílio da noite, horror sagrado, Onde jaz destruída a formosura, Abre-te, dá lugar a um desgraçado:

Eis desço... eis cinzas apalpo... Ah Morte dura! Ah Tirsália! Ah meu bem, resto adorado!...

Torna, torna a fechar-te, oh sepultura!

(BOCAGE, 1994, p.14)

conduzem o leitor atual e mesmo do século XIX a uma ambiência cujo sombrio e morbidez da atmosfera pouco se distinguem do que encontra em poemas ultra-românticos, como o conhecido "Noivado do sepulcro", de Soares Passos, para me manter na mesma temática. Mesmo registro apresentará outro soneto de Bocage, "Insônia":

Oh retrato da morte, oh Noite amiga Por cuja escuridão suspiro há tanto! Calada testemunha de meu pranto, De meus desgostos secretária amiga!

Pois manda Amor, que a ti somente os diga, Dá-lhes pio agasalho no teu manto; Ouve-os, como costumas, ouve, enquanto Dorme a cruel, que a delirar me obriga: 
E vós, oh cortesãos da escuridade, Fantasmas vagos, mochos piadores, Inimigos, como eu, da claridade!

Em bandos acudi aos meus clamores;

Quero a vossa medonha sociedade, Quero fartar meu coração de horrores. (BOCAGE, 1994, p.27)

Essa ligação poética desesperada - nitidamente não neoclássica de Bocage 4 com o tema da morte é certamente um dos elementos que motivaram Álvares de Azevedo, autor de uma obra literária caracterizada pela tonalidade mórbida, a enxergar no poeta português setecentista uma espécie de confrade e modelo. Mas a admiração azevediana não se mostra limitada à obra, expande-se ao homem. A vida do autor de Rimas tem muito daqueles ingredientes que o romantismo elegerá como inescapável sina do artista genial: o infortúnio amoroso, a rebeldia, a libertinagem, os transtornos financeiros... em síntese, toda a manifestação do deslocamento existencial romântico, da incompatibilidade do gênio com as estruturas sociais. Álvares de Azevedo valeu-se também dessa imagem de poeta genial e dissoluto para incorporá-lo, de diversas maneiras, como vimos no início deste artigo, em sua obra. Como personagem azevediano, Bocage sempre se encontra em ambientes degradados da boêmia. O velho que, em Noite na taverna, entra no estabelecimento e interrompe a narrativa de Bertram, entre os feitos de sua vida, como o de cumprimentar Napoleão, recorda-se: "Bebi numa taverna com Bocage o Português".(AZEVEDO, p.578).Em "Glória moribunda", o poeta, que morrerá em breve nos braços de uma prostituta, numa calçada à noite, conta:

\footnotetext{
4 Zenóbia Collares Moreira, em Pré-romantismo português, livro em que defende, a propósito, o 'pré-romantismo' como corrente literária específica e com autonomia estética em relação ao neoclassicismo e ao romantismo, cita obras de outros autores portugueses do período que apresentam temática 'noturna e sepulcral', entre os quais: As noites josefinas (1770), de Luís Rafael Soyé; A sepultura de Lésbia (1792), de Tomás António Santos e Silva, e Nênias ou sentimentos paternais no sepulcro de Perpétua em três noites (1818), de Francisco Joaquim Bingre. (cf. MOREIRA, 2000, p.179-192.)
} 
Eu fui à noite da taverna à mesa Bater meu copo à taça do bandido, $\mathrm{Na}$ louca saturnal beber com ele, Ouvir-lhe os cantos da sangrenta vida $\mathrm{E}$ as lendas de punhal e morticinio. (AZEVEDO,p.300).

Penseroso diz, em Macário: "A descrença é uma doença terrivel: destrói com seu bafo corrosivo o aço mais puro: é ela quem faz de Rembrandt um avarento, de Bocage um libertino!..." (AZEVEDO, p.552).E, em Literatura e civilização em Portugal, texto em que Álvares de Azevedo mais explicita a imagem poético-biográfica que concebia de Bocage, fornece estes retratos:

[...] não vedes pelo tremedal das ruas da Lisboa imunda do século XVIII um homem que cambaleia e tropeça, roto $\mathrm{e}$ desabotoado a encostar-se pelas esquinas, tateando as paredes no andar vertiginoso? Lançai um olhar por essa janela a meio cerrada... Não vedes ali na sombra do lupanar o semblante espavorido, o olhar incerto e uns cabelos louros espalhados pela fronte alta, na mão ainda o copo vermelho, nos joelhos a mulher perdida, como o esboço sublime de Holbein, o libertino pintor Alemão, à margem do Elogio da loucura de Erasmo, na biblioteca Bale? (AZEVEDO, p.736).

Mais adiante,

Então, na velha Lisboa [...] terieis visto à tarde, com os cotovelos nas mesas torpes da taverna, a cabeça desgrenhada e loura, ou, ébrio e cambaleante, no seu entusiasmo febril - agitando a fronte acesa dos vinhos, cintilar aqueles olhos azuis, onde o fogo d'alma lhe passava como ao través de uma lâmpada de alabastro - e as palavras sonoras, os versos túmidos, e as idéias fervorosas a transbordarem-se-lhe dos lábios eloqüentes - e a improvisação cada vez mais viva, a brotar como dos beiços do vulcão... E depois a cabeça tornava-se mais vacilante, o olhar mais esgazeado do alucinar, e o rei da plebe, aos aplausos das turbas, rodava dali, imóvel, turvo - como um corpo bruto. (AZEVEDO, 2000, p.737).

Se, quanto ao tratamento da morte, encontramos uma proximidade senão afinidade entre as duas liras - a bocagiana e a azevediana -, quanto à libertinagem como característica biográfica não precisamos verificá-la na vida do poeta brasileiro, assim como 
enxergava ser na vida do poeta português. Se uns defendem o homem Álvares de Azevedo ‘anjo' e outros como 'demônio', não nos importa. Importa-nos, sim, que a obra da Álvares de Azevedo revela um universo de degradação boêmia, a exemplo do protagonista de Macário, do narrador de O poema do frade, dos personagens-narradores de Noite na taverna e da ambiência geral que marca a segunda parte de Lira dos vinte anos, como neste soneto:

\footnotetext{
Um mancebo no jogo se descora, Outro bêbado passa noite e dia, Um tolo pela valsa viveria, Um passeia a cavalo, outro namora.

Um outro que uma sina má devora Faz das vidas alheias zombaria, Outro toma rapé, um outro espia... Quantos moços perdidos vejo agora!...

Oh! não proíbam pois ao meu retiro Do pensamento ao merencório luto A fumaça gentil por que suspiro.

Numa fumaça o canto d'alma escuto... Um aroma balsâmico respiro, Oh! deixai-me fumar o meu charuto! (AZEVEDO, p.238-239).
}

Trata-se, pois, de observar a condição no mundo que caberia ao poeta-gênio, segundo Álvares de Azevedo (ou, pelo menos, aquele Álvares de Azevedo orientado pelo veio-Calibã): tanto a de socialmente marginalizado, de ser "um doido que se aponta ao dedo" (AZEVEDO, p.299), como lemos em "Glória moribunda" assumir-se o próprio Bocage-personagem, quanto a de corrompido perante os valores de uma arte divinizada, sendo o dinheiro - mais "santo dos que os Papas" - "o Deus de Bocage" (AZEVEDO, p.244)e de todos os poetas, desde Homero a Byron, como vemos no poema "O Editor", da segunda parte de Lira dos vinte anos. O caso biográfico de Bocage como exemplo da concepção azevediana do lugar dos poetas na sociedade é, com efeito, pertinente e interessante para pensarmos a presença do poeta português na obra do 
brasileiro, mais do que pinçar infrutíferas coincidências biográficas entre os dois autores.

Avancemos. De fato, Manuel Maria du Bocage será para Álvares de Azevedo um gênio, dotado, como vimos no trecho mais acima transcrito de Literatura e civilização em Portugal, de uma capacidade vulcânica de declamar versos improvisados e receber aplausos inflamados, donde o vermos também citado no poema "O Editor" ao lado de, além de Homero e Byron, Virgílio, Horácio, Tasso, Racine, entre outros. Se o propósito deste artigo é, além de iluminar os contornos da imagem azevediana de Bocage, o de compreender como a presença do poeta português nos ajuda a compreender a poesia do brasileiro, um trecho dessa parte de Literatura e civilização em Portugal é de fundamental importância. Ei-lo abaixo transcrito:

Porém Bocage não é sempre o engenho dormido na perdição, o cisne com as asas abertas caindo no pantanal, o soldado libertino, ébrio no bordel. Às vezes, quando a fronte lhe latejava mais fresca às virações da primavera, quando coração lhe batia mais macio, e uns olhos puros de mulher se miravam na lagoa azul da cisma do cantor, então a corda argentina da candidez virginal the revivia n'alma, como lágrimas cristalinas de perfume, os belos sonetos tão belos que nem sonhos de Petrarca à bela Italiana, lhe gotejavam dos lábios como a chuva dos rosais em flor. (AZEVEDO, p.740-741).

Ora, a passagem que descreve a poética bocagiana, com pequenos ajustes, serviria, em sua substância, para descrever a poética do próprio Álvares de Azevedo, aliás, tão bem esclarecida por ele mesmo no prefácio à segunda parte de Lira dos vintes anos: “[...] a unidade deste livro funda-se numa binomia. Duas almas que moram nas cavernas de um cérebro pouco mais ou menos de poeta escreveram este livro, verdadeira medalha de duas faces" (AZEVEDO, p.190). Uma face, a do "mundo visionário e platônico"; a outra, a "ilha Barataria de D. Quixote, onde Sancho é rei"; ou na categorização poética sugerida no prefácio e desenvolvida por Antonio Candido, Ariel e Calibã. Teríamos, pois, a correspondência entre "a bela face do coração de Bocage" (AZEVEDO, p.741)e a faceta-Ariel, de um lado, e de outro, entre o "engenho dormido 
na perdição" (AZEVEDO,p. 740) do poeta português e a faceta-Calibã do brasileiro. Na verdade, a ideia de uma binomia psíquica a orientar a escrita poética, mais do que um auto-diagnóstico e a percepção do funcionamento criativo de um outro poeta específico, para Álvares de Azevedo, é caráter próprio do gênio, algo sugerido nesse trecho do prefácio: "Depois dos poemas épicos Homero escreveu o poema irônico. Goethe depois de Werther criou o Faust. Depois de Parasina e o Giaour de Byron vem o Cain e Don Juan" (AZEVEDO,p.191), e explicitamente afirmado na primeira linha do estudo sobre Jacques Rolla, de Alfred de Musset: "O gênio é como Jano Latino: tem duas faces" (AZEVEDO, p.678),para o que se servirá, como exemplos comprobatórios, dos mesmos autores referidos no segundo prefácio de Lira dos vinte anos, com o acréscimo de Tom Moor e Musset. ${ }^{5}$ Embora Álvares de Azevedo veja a binomia como imanência ao gênio, havemos de observar que as características das faces da medalha diferenciar-se-ão de poeta para poeta, conforme determinados fatores. Em Literatura e civilização em Portugal, Azevedo, para explicitar os contornos da personalidade poética de Bocage, lança mão de um método comparativo, aproximando-o de Dante, Shelley, Chatterton, Ovídio, Musset, e principalmente de Byron e

\footnotetext{
5 Convém recordar, aqui transcrevendo palavras de Massaud Moisés que: "Existem dois Bocages: o que o vulgo fixou através de anedotas, verdadeiras algumas e falsas outras, mas todas raiando na obscenidade grosseira, e o que a tradição literária nos legou. Este é que importa, pois o primeiro segue trajetória secundária e infensa a qualquer configuração, visto o povo atribuir-lhe todos os ditos picantes que, não tendo paternidade conhecida, devem forçosamente pertencer a alguém. [...] // O segundo Bocage escreveu uma vasta obra poética fraccionada em dois setores fundamentais: o satírico e o lírico." (MOISÉS, 1969, p.120.) Álvares de Azevedo parece compreender a criação poética binômica do poeta português em conformidade com esta divisão em "dois setores" de sua obra divulgada pela tradição literária: "o satírico e o lírico", e não com a existência desses dois Bocages referidos por Massaud Moisés. É que, no prefácio a $O$ conde Lopo, em meio à discussão sobre os conceitos de belo, num ponto em que afirma que "O imoral pode ser belo", mas, por exemplo, "Algumas odes imorais de Horácio, não o são", e, desse modo, concluindo que, assim como "Do sublime ao ridículo há um passo", "do imoral ao torpe também vai um passo", (AZEVEDO, p. 378) o poeta brasileiro escreve: "Dos cantos de Byron, ardentes como o tremor do enlevo no sorver dos beijos - vai um passo talvez a esses poemas infames, corrompidos e corruptores imputados ao grande sonetista de Portugal." (AZEVEDO, p. 378) A dúvida revelada pela palavra 'imputados' quanto à autoria de Bocage desses poemas (ao que tudo indica, trata-se do repertório fescenino) somada aos adjetivos associados a tais textos, leva-nos a crer que, na binomia bocagiana, segundo a concebe o autor de Noite na taverna, somente se consideram a poesia lírica e a satírica transmitidas pela tradição literária.
} 
Werner. Mas, por outro lado, em coerência com sua concepção, explicitada logo no início do estudo, de que mudadas "as relações do país e a literatura muda" (AZEVEDO, p.708), também aponta para diferenças:

[...] se as brisas nevoentas do Norte lhe houvessem influído a irritabilidade nervosa, a melancolia hipocondriaca e spleenética, a insânia tocada de superstição, o histerismo das terras nevoentas, esse homem houvera sido - Chatterton, Byron ou Werner...(AZEVEDO, p.738)

Além de fatores climáticos, Azevedo assinala fatores culturais nessa distinção:

Dessem a esse Português a cópia de instrução que mana caudal na Alemanha, embalassem-no aos lieders [sic] da superstição teutônica, dessem um ar em que voasse a águia da imaginação fervorosa de Bocage; apontassem-lho o quadro sublime para que o Correggio exclamasse: anch'io son pittore - e... Bocage fora Werner.(AZEVEDO, p.739).

Chegamos ao ponto nevrálgico de nosso artigo. Aqui Álvares de Azevedo parece declarar, nas entrelinhas de seu estudo ensaístico, que o poeta com quem mais se identifica e pode identificar-se não seria Byron, Musset ou Lamartine, mas o setecentista português. O fato se insinuaria já no postulado, "sem língua à parte não há literatura à parte" (AZEVEDO, p.715), de modo que os brasileiros poderiam chamar seus a obra de Camões e a de Bocage, aliás, como deixa entrever o poeta brasileiro, mais significativas do que a de Santa Rita Durão e Silva Alvarenga. Mesmo no caso de literaturas escritas em línguas já distintas, como a portuguesa e a espanhola, defende Azevedo:

[...] é tanta a similitude do parecer, tanta a ilusão dos sonhos poéticos, são tão reflexivos numa e noutra os toques da cavalheirosa desfreima, os sentimentos altivos dos peninsulanos, desses Cids tão robustos como a loriga, desde os plumões da cervilheira até as grevas onde ressoa o argentino tinir dos acicates; que se fosse possivel passar por esse tropeço do vário das línguas, pudéramos dizer que essas duas, eram uma só literatura.(AZEVEDO, p.716). 
Disso extraímos: Álvares de Azevedo demonstra que, no uso da mesma língua e nas características da sociedade brasileira, que ainda não tivera tempo para diferenciar-se da portuguesa, senão cerca de duas ou três décadas, desde a independência política, proclamada em 1822, o que se escrevia aquém e além mar constituiria "uma só literatura". Assim, se Byron ou Werner, por imposição de determinados fatores, diferenciavam-se de Bocage em certa medida, davam-se condições para haver uma mais plena identificação entre Bocage e Azevedo do que entre este e aqueles outros.

No prefácio à segunda parte de Lira dos vintes anos, lemos: "Há uma crise nos séculos como nos homens. É quando a poesia cegou deslumbrada de fitar-se no misticismo e caiu do céu sentindo exaustas as suas asas de oiro." (AZEVEDO, p.190) .Evidentemente, o autor dessas linhas atribui a seu livro o estatuto de registro dessa crise, crise de um século (o XIX) cindido entre "as desesperanças materialistas da filosofia Francesa daquela época [o século XVIII], como a definiu Lamartine, toda matemática, e o idealismo de Kant e Fichte" (AZEVEDO, p.737) segundo consta em Literatura e civilização em Portugal como caracterização da denominada "fase negra", na qual Bocage teria vivido e escrito. Se, para Azevedo, "Bocage não é um caráter estéril - por único - no historiar da literatura portuguesa" e nele "traduz-se uma era inteira", o próprio autor brasileiro parece querer assumir-se na qualidade de herdeiro da poética bocagiana, herdeiro legítimo perante a defesa de não haver divisão ainda entre a literatura de Portugal e do Brasil.

A análise da presença de Bocage na obra de Álvares de Azevedo, de fato, esclarece muito sobre o poeta brasileiro. A dimensão de sua auto-consciência histórico-poética torna-se mais nítida e conseguimos ver contornos antes despercebidos, sem um foco direcionado a essa intima ligação do autor de $O$ conde Lopo com o de Rimas, principalmente no que diz respeito à questão das duas faces que 
caracterizam a produção literária azevediana. Da tola e desinformada imagem de um ultra-romântico irracionalista, egótico e fugitivo da realidade dá-se mais um passo rumo à consolidação da imagem de um poeta auto-reflexivo, que pensou criticamente seu próprio processo criativo e seu lugar na tradição literária luso-brasileira.

\section{Referências bibliográficas:}

AZEVEDO, Álvares de. Obra completa. Rio de Janeiro: Nova Aguilar, 2000.

BAPTISTA, Abel Barros. O cânone como formação: a teoria da literatura brasileira de Antonio Candido. In: O livro agreste. Campinas: Unicamp, 2005. pp. 41-80.

BOCAGE, M. M. Barbosa du. Sonetos. Belo Horizonte; Rio de Janeiro: Garnier, 1994.

CANDIDO, Antonio. Álvares de Azevedo, ou Ariel e Calibã. In: Formação da literatura brasileira. Belo Horizonte: Itatiaia, 2000. Vol. 2, pp. 159172.

CIDADE, Hernâni. Bocage. 2. ed. Lisboa: Editorial Presença, 2005. GUINZBURG, Jaime. Portugal, nação melancólica: Bocage interpretado por Álvares de Azevedo. Disponível em:

<http://www.geocities.com/ail_br/portugalnacaomelancolica.htm>. acesso em: 18 mar. 2009.

MOISÉS, Massaud. A literatura portuguesa. 7. ed. São Paulo: Cultrix, 1969.

MORAES, Zenóbia Collares. O pré-romântico português. Natal: Central de Cópias, 2000.

PANOFSKY, Erwin. Et in arcadia ego: Poussin e a tradição elegíaca. In: O significado nas artes visuais. 3. ed. São Paulo: Perspectiva, 2009.

SARAIVA, António José; LOPES, Óscar. História da literatura portuguesa. 5.ed. Porto: Porto Editora; Lisboa: Empresa Lit. Fluminense, [s.d.) 